\title{
O CONTEXTO DOS NOVOS RECURSOS TECNOLÓGICOS DE INFORMAÇÃO E COMUNICAÇÃO E A ESCOLA
}

\author{
Maria Apparecida Campos Mamede-Neves ${ }^{*}$ \\ Rosalia DuARTE* $^{* *}$
}

\begin{abstract}
RESUMO: O presente artigo analisa as tensões vividas pela escola brasileira face ao acelerado desenvolvimento tecnológico das últimas décadas, tomando como referência pesquisas, realizadas no Brasil e no mundo, sobre modos de uso e de apropriação das tecnologias da informação e da comunicação adotados por crianças e jovens e, ainda, estudos que analisam o impacto disso nos processos cognitivos. Sem perder de vista o importante papel desempenhado pela educação escolar na formação de identidades e na construção e transmissão de conhecimentos e valores, o texto examina, criticamente, o que, em realidade, a escola incorpora das novas tecnologias e o que pode ainda vir a incorporar, levando o leitor a considerar possíveis estratégias que ajudariam a delinear novos cenários escolares e novos modos de potencializar os caminhos do conhecimento e da aprendizagem efetiva.
\end{abstract}

Palavras-chave: Tecnologias da informação e da comunicação. Escola contemporânea. Juventude. Mídia.

\section{THE CONTEXT OF THE NEW TECHNOLOGIES OF INFORMATION AND COMMUNICATION AND SCHOOL}

ABSTRACT: The present article analyses the tensions present in Brazilian schools in light of the accelerated technological development of the last few decades. We survey research, done in Brazil and in other countries, on how information and communication technologies are

* Doutora em Psicologia e professora titular do Departamento de Educação da Pontifícia Universidade Católica do Rio de Janeiro (PUC-RIO). E-mail: apmamede@edu.puc-rio.br

** Doutora em Educação e professora associada do Departamento de Educação da PUC-RIO. E-mail: rosalia@edu.puc-rio.br

Educ. Soc., Campinas, vol. 29, n. 104 - Especial, p. 769-789, out. 2008 
used and appropriated by children and young people, together with studies that analyses the impact of these technologies on cognitive processes. Without losing sight of the important role of schooling in the construction of identities, as well as the construction and transmission of knowledge and values, the text critically examines what new technologies schools have incorporated and what they can still incorporate, inviting the reader to consider possible strategies that help delineate new school scenarios and new ways of stimulating the paths to knowledge and effective learning.

Key words: Information and communication technologies. Contemporary schools. Youth. Media.

\section{Introdução}

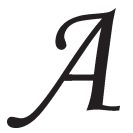

importância dos novos recursos tecnológicos de informação e comunicação na construção do conhecimento tem sido motivo de muitos debates e muitas controvérsias. Philipe Breton (2000), pesquisador do Laboratório de Sociologia da Cultura Européia de Strasbuorg e professor da Universidade Paris I (Sorbonne), classifica seus autores em três grandes posiçôes: "os que são militantes do grupo 'tudo é internet', prosélitos de uma nova cultura; os tecnofóbicos, hostis a qualquer técnica, e os que pensam que o uso racional da tecnologia da informação pode, em certas condições, ser fator de progresso" (p. 13). Os primeiros defendem um só ponto de vista possível e legítimo para essa questão, calcados na crença de que somente haverá um mundo melhor graças à instauração de uma sociedade mundial de informação; os segundos ainda constituem a maioria, segundo Breton; vêem a tradicionalidade das fontes do conhecimento com as qualidades de Paladino, ${ }^{1}$ em oposição às novas tecnologias da informação e da comunicação, uma "caixa de Pandora": um alerta mitológico à curiosidade de homens e mulheres, uma verdadeira lição de prudência. $^{2}$ Os terceiros, dentre os quais, segundo o autor, está hoje a maioria dos docentes, avaliam como positiva a possibilidade de incorporar, reconhecer e aproveitar as vivências dos alunos com as tecnologias que estão para além do espaço escolar, no sentido de construir e desenvolver eficientes práticas pedagógicas. É, portanto, dentro desta última concepção que este artigo se propóe a refletir sobre a escola no contexto das inovações tecnológicas em informaçãao e comunicação. 
Possibilidades míticas e reais das novas tecnologias da informação e da comunicação

É recorrente a visão de que as novas tecnologias da informação e da comunicação (TIC) são capazes, por elas mesmas, de promover informação, comunicação, interação, colaboração e, em conseqüência disso, de construir novos conhecimentos. É fato o vertiginoso aumento da velocidade na transmissão de informaçôes; é fato, também, a ampliação da possibilidade da comunicação entre diferentes países e povos do planeta; e é verdade que é possível, hoje, colocar diferentes pessoas em contato, ao mesmo tempo, rompendo barreiras geográficas e temporais. Entretanto, os modos de interação e de colaboração que serão estabelecidos entre essas pessoas, assim como o que elas vão fazer com essa possibilidade de contato, não são tão óbvios e não são pré-determinados ou mesmo controláveis; vão depender de quem está nos nós da rede que será tecida entre elas.

\section{A informação e a comunicação}

Informação e comunicação são conceitos que se complementam, mas que não podem ser considerados sinônimos. Etimologicamente, o termo "informação" advém do verbo informar, cunhado no século XV do latim "informare", que significava "dar forma, formar". Durante a Renascença, informar era sinônimo de "instruir". No século XX, seu significado foi expandido, passando a significar tanto "envio de mensagem", quanto "dar intelegibilidade" a algo. Dito de outro modo, a informação pode ser enviada e recebida, mas, para ir além disso, é preciso que se estabeleça um contrato entre emissor e receptor que implica codificaçãao e decodificação, assim como produção de significado e atribuição de sentido por parte de ambos.

Entende-se a produção de significado como a possibilidade de combinar códigos distintos na configuração de mensagens. Essas combinaçōes podem ter um caráter mais ou menos universal, como no caso da imagem (fixa e/ou em movimento) ou serem restritas a um determinado conjunto de pessoas e/ou culturas que compartilham um mesmo código lingüístico, por exemplo, cujo padrão de codificação é arbitrário e, em geral, para ser compartilhado, precisa ser ensinado/ aprendido (Santaella \& Noth, 2004). A produção de sentido tem um 
caráter mais singular, embora com determinações histórico-sociais e, ainda que não seja um processo totalmente autônomo em relação ao significado, depende fundamentalmente das condições de recepção e de fatores individuais, sociais e culturais que envolvem o receptor.

Por ser um processo muito mais complexo e sofisticado do que a simples transmissão de informações, construídas a partir de códigos lingüísticos pré-determinados, a comunicação exige a interação bilateral entre humanos, direta ou indireta, intencional ou não-intencional, verbal ou não-verbal, visual, sonora ou seguindo outros fluxos. Como nos diz Eco (1987, p. 4), "Todos os fenômenos de culturas são sistemas de signos, isto é, fenômenos de comunicação".

\section{A interação e a colaboração}

A interação e a colaboração são conceitos que se entrelaçam, sendo que o primeiro é a condição sine qua non do segundo. Interação é a ação recíproca de duas ou mais pessoas, é o conjunto das ações e relações entre os membros de um grupo ou entre grupos de uma comunidade; pressupõe diálogo, mas nem sempre resulta em colaboração. Esta, para existir, precisa ultrapassar a própria interação; tem que ser uma atividade compartilhada, em que, nas trocas e influências recíprocas, há sempre o desejo de estar dentro de um espaço interacional, compartilhando interesses e "olhando" na mesma direção.

Assim sendo, há um simplificação perigosa quando se restringe interação e colaboração à realização de um conjunto de tarefas ou atividades dentro de um mesmo ambiente, propiciado por um programa de computador. O suporte pode viabilizar contatos, reduzir distâncias, "apagar" o tempo, mas a colaboração depende do propósito de cada um dos integrantes da rede de contatos e, sobretudo, das ações que serão implementadas ali. Desse modo, a interatividade, conseqüência da interação, será apenas a abertura para mais comunicação, mas não necessariamente para mais trocas, mais participação e maior compromisso com o que está sendo produzido ou informado. $\mathrm{O}$ conceito de interação, em sua acepção mais plena, implica

(...) a disponibilização consciente de um "mais comunicacional" de modo expressivamente complexo, e, ao mesmo tempo, atentando para as interações existentes e promovendo mais e melhores interações - seja 
entre usuário e tecnologias comunicacionais (hipertextuais ou não), seja nas relações (presenciais ou virtuais) entre seres humanos. (Silva, 1999, p. 155)

Quando se está lendo um livro, assistindo a um filme em DVD, por exemplo, podemos retornar a algum ponto que ficou para trás, saltar capítulos ou adiantar a fita, ao sabor do que estamos procurando, coisa que não é possível numa sessão de cinema, a não ser que vejamos o filme todo outra vez.

Apesar de o vídeo oportunizar esse avançar e retroceder, expressando algum nível de intervenção, isso ainda não satisfaz a necessidade que temos de redirecionar o fluxo comunicativo. O mesmo ocorre com o controle remoto quando o usuário faz o zapping, alternando entre os canais disponíveis, sejam eles 5 ou 150. (Picanço et al., s/d,).

Para poder efetivamente interagir, modificando o curso do que está sendo construído, para trabalhar nessas interações de forma colaborativa, é certo que precisamos de artefatos que, construídos pelos homens, podem favorecer a colaboração entre eles, mas não são, em si mesmos, garantia desta postura. Há que se dar um passo além.

\section{O conhecimento e o entendimento: nas malhas da cognição}

A cognição é ainda considerada, na rubrica de alguns dicionários, por exemplo, Houaiss, um dos três tipos de função mental (nele, as funções mentais estão divididas em afeto, cognição e volição); no dicionário Aurélio, cognição significa o conjunto dos processos mentais usados no pensamento, na percepção, na classificação, reconhecimento e, na definição de Michaelis, cognição é o adquirir conhecimento. Acresce-se a isso o fato de algumas pessoas entenderem que a cognição é o próprio ato da aprendizagem e que aprendizagem é conhecimento. Assim sendo, estamos diante de um termo polissêmico, ou seja, parafraseando Kurt Lewin (1951), um termo com vários significados e uma história confusa. Se acrescentarmos a isso o fato de que aprendizagem também é polissêmica, temos a necessidade de aclarar, e muito, esses termos.

Aprendizagem é um processo que vai além do processo cognitivo, porque não só corresponde a mudanças estáveis (mas não imutáveis) de estruturas cognitivas, ou seja, formação de redes no campo, diferenciação 
de áreas (não estruturadas, estruturadas em um todo, reestruturadas numa nova dimensão homóloga ou não à anterior, mas cujo produto se apresenta diferente); também engloba mudanças de interesse, chamadas pelo autor de valências (relação entre região do sujeito e regiōes de atração) e, ainda, mudanças de valores e ideologias. Autores como Sara Pain (1999) encampam essa compreensão quando concebem a cognição como função precípua do sujeito do conhecimento, englobando três dimensões: racional, desiderativa e social - podendo esta ser relacional e contextual. ${ }^{3}$

Aliás, tanto os trabalhos investigativos de natureza teórica, como, por exemplo, a contribuição de Freud sobre a metapsicologia dos processos de pensamento (escrito em 1895 [1977]), quanto os de natureza eminentemente empírica, como, por exemplo, os estudos de Damásio (1996) e Battro et al. (2008), desenvolvem uma forte argumentação contra a idéia de que a cognição não passa de um mecanismo de processamento de informações, um software cujo bom desempenho depende apenas do potencial do hardware no qual está instalado, neste caso, o cérebro, ambos pensados como autônomos em relação às demais partes do corpo e, muitas vezes, até mesmo à vida social. Essa é uma visão corrente no senso comum, que, infelizmente, também está presente em muitos autores do campo comunicacional, em relação às mídias.

Cognição é, também, muito mais do que simples processamento de informaçōes. É, sobretudo, análise, julgamento e crítica e implica articulação permanente entre razão e emoção. Segundo Damásio (1996, p. 13):

Somos confrontados com a incerteza quando queremos fazer um juízo moral, decidir o rumo de uma relação pessoal ou planejar a vida que nos apresenta pela frente. As emoções e os sentimentos, juntamente com a oculta maquinaria fisiológica que lhes está subjacente, auxiliam-nos na assustadora tarefa de fazer previsóes relativamente a um futuro incerto e planejar nossas ações de acordo com essas previsões.

A fala de Damásio levanta não só o papel das incertezas, como a função do erro no âmbito da cognição. $O$ erro e a verdade fazem parte do mesmo campo psíquico e se inscrevem numa série que vai da falsificação completa à veracidade absoluta; são partes, também, da estratégia cognitiva, fruto de uma instância que decide quando o conhecimento é verdadeiro ou quando a supressão do mesmo se faz necessária 
(Rouanet, 1993). Isso só é possível pela função construtiva do erro, que permite ao pensamento repassar o que antes teceu, encontrar o elo perdido e restaurar a cadeia associativa que lhe confere significação.

Assim, nesse sistema complexo, o pensamento, como uma imensa rede associativa em metamorfose permanente, configura-se como um processo de formação de significações - também chamado de semiose ou processo sígnico - pelo qual alguma coisa (signo) representa outra (objeto), sob algum aspecto ou modo (interpretante), para um sujeito (intérprete); série de características funcionais e estruturais da representação ligadas a um saber referente a um dado objeto (Eco 1987). O pensamento "pula" de uma representação para outra, desenha trilhas que se bifurcam; tece tramas. Em sua hipertextualidade, se organiza em um modo "fractal", no qual qualquer nó pode se revelar como uma rede que leva a outra rede, que leva a outra rede..., sendo "mantido na trilha" pelo controle da percepção seletiva ligada à realidade (Mamede-Neves, 2004)

Ostrower (1998) nos ajuda a compreender essa complexidade quando a define como um alto nível de organização de um fenômeno:

(...) um modo específico pelo qual se interligam os componentes, estabelecendo-se um equilíbrio dinâmico - um equilíbrio ativo, nunca passivo ou mecânico. Em vez de uma combinação de fatores aleatórios e desconexos (...), lidamos com configuraçôes que apresentam um alto grau de integração coerente. (p. 197)

Para a autora, dessa integração de múltiplos componentes surgem novas totalidades, cujo caráter é "qualitativo, não-quantitativo, fundamentando-se em processos recíprocos e reiterativos, isto é, nãolineares e, por isso mesmo, nem sempre mensuráveis, previsíveis ou programáveis". Trata-se, então, da produção de sínteses sucessivas, que resultam de "processos de transformação e não de somatório", o que as torna irreversíveis a um estado anterior, ou irredutíveis aos componentes anteriores (Ostrower 1998, p. 197-198).

Assim, de tudo que pudemos trazer ao debate, pode-se inferir que o conhecimento só se estrutura no âmbito da interpretação que, por seu turno, pressupóe entendimento.

Afirmar, pois, de forma simplista, que as novas tecnologias, por si mesmas, aumentam a cognição, desenvolvem o raciocínio ou ampliam 
a inteligência é ignorar a complexidade do processo cognitivo que resulta na aquisição de conhecimentos. Como acontece com qualquer outro artefato produzido pelo homem (roda, lápis, papel, máquina de escrever, telefone, televisão etc.), saber operar com os recursos tecnológicos, neste caso, da informação e da comunicação, tanto pode envolver apenas uma pequena dose de cognição, com sínteses muito básicas, quanto pode exigir um esforço imenso para a integração de componentes distintos de uma imensa rede de significaçóes e para a produção de estratégias hipotético-dedutivas, nas quais o pensamento crítico é essencial (Mamede-Neves, 2004).

Assim considerando, passa a ser plausível uma homologia entre o hipertexto cibernético e o pensamento humano que, como já dissemos se processa com base em um complexo sistema de redes interligadas. Nessa perspectiva, fica mais verossímil a hipótese de que a hipertextualidade presente nas novas tecnologias de informação pode ajudar a entender as tramas que estão por trás da emergência do pensamento, ou seja, a metacognição (a "cognição sobre a cognição").

Metacognição refere-se, entre outras coisas, ao monitoramento ativo e à conseqüente regulação e orquestração desses processos em relação aos objetos cognitivos ou dados sobre os quais eles incidem, usualmente a serviço de alguma meta ou objetivo concreto. (Flavell, 1985, p. 29)

Em outras palavras, a metacognição é "o conhecimento, a consciência e o controle que a pessoa tem de seus processos cognitivos. Pensar metacognitivamente é exatamente ser capaz de pensar o seu próprio pensamento, tomando ciência dos conteúdos mentais presentes em sua esfera psíquica” (Nunes, 2006, p. 240).

Porém, a metacognição só se permite ser traduzida, semiótica e semanticamente estruturada, se entendida como um mecanismo de significação, como forma de apreender o real não de maneira direta e imediata e sim através de conceitos, de construçôes sociais que os fazem mudar ao longo do desenvolvimento (Flavell, 1985; Maia \& Bittencourt, 2006).

Por outro lado, o conhecimento, para ser efetivamente conhecimento, tem que ser mais do que um estoque de dados linearmente organizados. Para que esses dados façam sentido, ou seja, para que sejam integrados e sintetizados, tem que haver o que escolhemos aqui chamar 
de entendimento, ou seja, eles precisam entrar na ordem da significação mais complexa, sobre a qual podemos ter uma infinidade de mapas conceituais.

Assim, para efetivamente contribuir para o conhecimento enquanto entendimento, o domínio das tecnologias tem de favorecer os processos metacognitivos que permitem uma análise crítica das informações e, o mais importante, pressupõem sociação (sociabilidade), nos termos propostos por Simmel (1983), ou seja, interação igualitária entre desiguais em torno de objetivos e conteúdos comuns. A escola tem muito a contribuir nesse processo, pois é um espaço privilegiado de sociabilidade.

Juventude e novas TIC

As TIC com as quais convivemos hoje nos permitem vislumbrar o que virá a seguir, mas, certamente, muito do que ainda está para ser desenvolvido é ainda inimaginável para a maioria dos que não estão familiarizados com essa área. Porém, crianças e jovens "nativos digitais" (Prensky, 2001), os que chegaram ao mundo após a popularizaçăo dos computadores pessoais e a criação da internet, compõem um segmento de usuários de TIC que não só faz uso corrente das mesmas como, também, antecipa o que está por vir, explora de forma criativa e diversificada tudo o que essas tecnologias têm a oferecer, ultrapassando, inclusive, os limites originalmente estabelecidos para o uso regular delas. Diferente, portanto, da imensa maioria dos professores que, pelas suas idades, são, em geral, imigrantes digitais.

Estudos com jovens de ensino médio (Keegan, 2002; Rivoltella, 2006) foram realizados em diversos países da Europa, buscando captar a avaliação de jovens usuários quanto à interface gráfica e audiovisual, acessibilidade, compreensão, apropriação, navegabilidade, capacidade de interatividade destes artefatos.

Uma investigação desse tipo, Jovens em rede, realizada no Departamento de Educação da PUC-RIO, ouviu quase mil jovens do terceiro ano do ensino médio, $51 \%$ mulheres e $49 \%$ homens, com idades entre 17 e 19 anos, provenientes de diversos bairros do Rio de Janeiro e com diferenças significativas de classe. $\mathrm{O}$ tema em estudo era a relação desses jovens com as TIC e, em particular, as representaçôes que faziam da internet (Mamede-Neves, 2008). 
$\mathrm{O}$ estudo constatou que esses jovens elegem a internet como o espaço privilegiado de construção de conhecimentos, de possibilidades de encontro, de comunicação e de lazer, pelas múltiplas possibilidades que ele oferece ao articular imagem e texto, de forma indissociável. Segundo Barthes (1964), na relação recíproca entre texto e imagem, as palavras, assim como as imagens, atuam como "fragmentos de um sintagma mais geral e a unidade da mensagem se realiza em um nível mais avançado” (p. 38). Esse talvez seja um dos fatores pelos quais os jovens percebem a internet como um ambiente que favorece a aprendizagem.

Brandão e Martinez (2006) apresentam resultados de uma pesquisa sobre estratégias familiares de escolarização, realizada em escolas de alto prestígio da cidade do Rio de Janeiro. Segundo as autoras, "uma das dimensões mais relevantes na caracterização do grupo estudado [famílias de alto poder aquisitivo], no campo das práticas culturais, é o acesso à informação" que estaria diretamente vinculado "ao uso de novas tecnologias de informação, consideradas não só como um simples meio - pois produzem, armazenam e transmitem o capital-informação -, mas como vias de escoamento e orientação do fluxo de trocas materiais e simbólicas".

Embora não discuta estratégias de acumulação de capital, a pesquisa Jovens em rede (Mamede-Neves, 2008) obteve resultados semelhantes quanto ao valor atribuído pelos jovens à informação, como bem simbólico, e quanto ao uso da internet como o principal meio para obter esse "valioso" bem.

Deixando de professar a primazia do texto impresso como fonte exclusiva de conhecimentos válidos, os jovens de hoje vêm migrando do livro, jornal e revistas impressos para a internet, onde acreditam poder encontrar tudo de que necessitam para se manter informados e vinculados ao seu grupo, assim como para aprender. Vale assinalar que os estudos que vimos desenvolvendo (Mamede-Neves, Costa \& Pedrosa, 2007; Duarte, Migliora \& Leite, 2006; Mamede-Neves, 2008) indicam que a relação de crianças e jovens com os conteúdos das mídias é sempre filtrada por juízos de valor que se constroem em função da inserção deles na sociedade. Ou seja, trata-se de uma relação mediada pela situação pessoal e pelas experiências de socialização vividas na família, escola, grupo de pares e assim por diante. Isso nos leva a crer 
que se trata de uma apropriação ativa, que lhes permite fazer uso produtivo dos conteúdos aos quais têm acesso.

Em relação ao que os jovens fazem em seu tempo livre, a pesquisa Jovens em rede verificou que 46,3\% preferem computador ao rádio, livros, revista e televisão e apenas $25 \%$ deles afirmaram ver televisão regularmente. Interessante notar que a televisão, mídia de massa mais popular na nossa sociedade, ainda que tenha tido uma considerável expressão nas respostas, ficou bem aquém do uso do computador. Acreditamos que, com o avanço tecnológico cada vez mais veloz, os computadores têm, a cada dia, ampliada sua capacidade hipermidiática, ou seja, as possibilidades de uso multifuncional se ampliaram, a diversidade de recursos se multiplicou e pode-se dizer que atividades que outrora ficavam restritas à televisão, hoje são realizadas no computador, como, por exemplo, assistir a filmes, jogar e ver videoclipes.

Limitando os dados apenas aos jovens da terceira série do ensino médio que tinham a chance de ingressar na universidade via PROUNI, provavelmente os de menos poder aquisitivo, a televisão é apontada por $43 \%$ desses jovens como principal mídia utilizada em casa e, em segundo lugar, o computador (18\%), o que pode estar relacionado a ter ou não acesso à rede. No entanto, mesmo assim, esses estudantes informam que navegam na internet, têm endereço eletrônico, participam de sites sociais, como o Orkut, têm seu próprio diário virtual (blogs e fotologs), utilizam programas de mensagem instantânea e de comunicação por voz e imagem, como MSN, Skype e MySpace, entre outros, e ainda procuram informações em igual proporção a de outros estudantes ouvidos.

O contato com a internet é uma unanimidade entre os jovens; $98 \%$ dos entrevistados na pesquisa informaram que navegam na internet diariamente ou, no mínimo, 2 a 3 vezes por semana. Isso sugere uma facilidade de acesso à rede também fora de casa. Os jovens de classes populares informam que têm acesso à internet em casa de amigos, na escola, no trabalho e em espaços como os cibercafés e quiosques de acesso pago (as chamadas lanhouses), hoje muito mais disseminados nas comunidades de baixa renda do que nas áreas mais privilegiadas das cidades.

Uma pesquisa sobre o uso das tecnologias da informação e da comunicação, realizada, em 2007, pelo Comitê Gestor da Internet no 
Brasil (CGI, 2008), indica que houve crescimento de mais de $100 \%$ no uso desses espaços, principalmente de lanhouses, estas últimas responsáveis, no momento da pesquisa, por quase $50 \%$ dos acessos de brasileiros à rede mundial de computadores, contra 43,39\% de acessos em casa, $25,3 \%$ no trabalho, $16,69 \%$ na casa de outra pessoa e apenas $18,48 \%$ na escola. Diz o relatório:

Antes focadas em clientes mais elitizados, de áreas nobres e shoppingcenters, hoje existem lanhouses espalhadas pelas periferias, aglomeradas e pelo interior do Brasil. Em muitas comunidades pobres existem centenas desses espaços. (...) São numerosos os exemplos de favelas que incorporam a internet em suas comunidades através de pequenas lanhouses. (...) Os jovens em sua maioria de baixa renda passaram a utilizar com freqüência e-mails, participar de comunidades de relacionamento, utilizar programas de mensagens instantâneas, promover pesquisas etc. Além da possibilidade de acesso ao conhecimento e à informação, grupos podem se manifestar e se expressar contribuindo decisivamente na produção de conteúdos. (CGI, 2008, p. 48)

Segundo o Comitê, as regiões Norte e Nordeste do Brasil foram as que apresentaram crescimento mais significativo no uso dos espaços públicos e pagos de acesso à internet, freqüentados, segundo o relatório, por $67 \%$ dos jovens de 10 a 24 anos, de menor nível de escolaridade e com renda mensal familiar inferior a um salário mínimo $(78 \%)$ (idem, ibid.).

Cabe assinalar que os resultados obtidos na pesquisa Jovens em rede (op. cit.) indicam que não há diferenças significativas entre os jovens entrevistados, no que diz respeito ao significado e valor atribuídos ao computador e à internet, assim como aos modos de representação e de uso dos mesmos, o que nos leva a colocar em questão a idéia corrente de que haveria um "analfabetismo digital" entre os jovens de baixa renda.

Além disso, a maioria dos que responderam ao questionário na pesquisa Jovens em rede demonstrou ter critérios mais ou menos elaborados para avaliar as condições ideais para a compreensão do conteúdo de um texto ou de uma página na rede. Alguns itens diretamente relacionados a características tipográficas, tais como quantidade de texto numa página, tamanho da fonte e contraste entre o fundo e o texto, foram considerados especialmente relevantes por eles para uma 
boa leitura na internet (aliás, sem dúvida, relevantes em qualquer suporte de leitura). Ilustraçôes - desenhos e fotos - assim como os esquemas gráficos foram também apontados como significativos nessa forma de leitura; porém, para eles, o som não acrescenta nada ao texto, talvez porque prefiram ouvir música em suportes paralelos (CD, MP3, ipod etc.) e falar ao telefone enquanto estão lendo.

Os estudos mencionados neste texto indicam, ainda, que as novas geraçōes estão integradas a uma nova cultura em formação, uma cultura em que a convergência das mídias vem transformando seu modo de viver e de ver o mundo, como aponta Morcellini (apud Rivoltella, 2006):

O fenômeno que se vai delineando é constituído da explosão de necessidades culturais e comunicativas sempre mais articuladas em um quadro - do ponto de vista do consumo - de integração entre mídias e gêneros comunicativos do que como os antagonismos competitivos do passado. Mesmo do ponto de vista da oferta, as lógicas predominantes hoje no mercado se endereçam, cada vez mais, a produtos culturais com declinações multimidiáticas. (Morcellini, 2005, p. 45, apud Rivoltella, 2006, p. 58; tradução livre)

Os novos cenários tecnológicos para a comunicação e a transmissão de informaçōes e a escola

Se levarmos em conta que a estrutura do hipertexto é homóloga ao modo como se estrutura o pensamento humano, podemos supor que os usuários regulares da internet têm a possibilidade de estar cotidianamente em um espaço que, de certo modo, traduz e torna visível sua própria maneira de pensar (Mamede-Neves, 2005).

Cabe considerar também as transformaçôes nas maneiras de ler, escrever, organizar e interagir com os textos que a navegação na internet ajudou a promover. Segundo Chartier (1999, p. 12-13):

A inscrição do texto na tela cria uma distribuição, uma organização, uma estruturação do texto que não é de modo algum a mesma com a qual se defrontava o leitor do livro em rolo da Antiguidade ou o leitor medieval, moderno e contemporâneo do manuscrito e do impresso, onde o texto é organizado a partir de sua estrutura em cadernos, folhas e páginas. $\mathrm{O}$ 
fluxo seqüencial do texto na tela, a continuidade que lhe é dada, o fato de que suas fronteiras não são mais tão radicalmente visíveis, como no livro que encerra, no interior de sua encadernação ou de sua capa, o texto que ele carrega, a possibilidade para o leitor de embaralhar, entrecruzar, de reunir textos que são inscritos na mesma memória eletrônica: todos esses traços indicam que a revolução do livro eletrônico é uma revolução nas estruturas do suporte assim como na maneiras de ler.

Em face disso, acreditamos que a escola precisa se deslocar das concepções de ensino/aprendizagem, nas quais o livro e ela própria se configuram como únicas possibilidades de aquisição de conhecimento e de cultura (tomada apenas como erudição), em direção a outras concepções, em que conhecimento, cultura e comunicação se aproximam, na medida em que são pensados a partir de novos parâmetros teórico/conceituais.

A indissociabilidade entre televisão, computador e tecnologia móvel (celulares, telefones multifuncionais - smartphones, assistentes pessoais digitais [PDAs] etc.), a chamada convergência das mídias já é uma realidade e tende a se tornar cada vez mais acessível em razão da demanda crescente e da conseqüente redução de custos de produção dos equipamentos. Dentro de pouco tempo, um mesmo suporte, estático ou móvel, ${ }^{4}$ permitirá que assistamos à televisão, acessemos arquivos de texto, imagem e som gravados na memória de nosso computador pessoal e, ainda, possamos ver filmes, criar nossos próprios filmes e páginas na internet, navegar e enviar mensagens de texto, imagem e voz.

As tecnologias móveis possibilitarão aos usuários fazer tudo isso e ainda participar de teleconferências, entrar em salas de bate-papo e assim por diante, a qualquer tempo e em qualquer lugar (Naismith et al., 2004), podendo, inclusive, armazenar aplicações e arquivos na própria rede (recurso já disponível atualmente), o que reduz, em muito, a necessidade de dispor de equipamentos com grande capacidade de armazenamento e, consequentemente, mais acessíveis. Isto é, espera-se do futuro (quase presente!) um maior acesso às tecnologias da informação para um número muito maior de pessoas, a custos bem mais baixos do que os praticados hoje. Isso não é bom nem é ruim em si mesmo: a qualidade e a aplicabilidade das informaçôes veiculadas, assim como a função social desses meios dependerão, fundamentalmente, do uso que venha a ser feito deles e dos objetivos a serem estabelecidos para esse uso. Precisamos, portanto, nos antecipar e apresentar 
propostas para uma discussão coletiva acerca do que se espera, no que diz respeito à educação, de todas essas possibilidades de comunicação.

Em artigo publicado neste mesmo periódico, Dwyer et al. (2007) fazem uma extensa revisão da literatura internacional referente a estudos empíricos sobre o impacto do uso de computadores na escola no desempenho escolar dos estudantes. Com base nesses estudos, afirmam que, "apesar da crença de que o uso de computadores traz amplos benefícios ao ensino fundamental e médio, não existe corpo de evidências empíricas baseadas em estudos de natureza experimental que sustente esta hipótese" (p. 6). Esses pesquisadores realizaram também um estudo empírico, a partir dos dados do SAEB, no qual estabelecem uma correlação estatística entre o desempenho em matemática de estudantes da quarta série com a resposta destes à questão do questionário específico para todas as séries: "Você utiliza o computador para fazer a lição de casa ou o trabalho que o professor de matemática passa?", cujas respostas podem ser "sempre, quase sempre, raramente, nunca". Os resultados desse cruzamento de dados, segundo os autores, demonstram que o uso intenso do computador, para todas as séries e para todas as classes sociais, diminui o desempenho escolar, sobretudo dos alunos pobres, o que os faz sugerir que sejam reconsideradas as políticas de implantação de computadores em escolas públicas brasileiras.

Parece-nos que o fato dos estudantes que fizeram uso mais intenso do computador para realizar as tarefas de matemática serem os que tiveram os piores resultados nessa matéria não autoriza uma afirmação tão genérica e conclusiva acerca de uma correlação direta entre o uso intenso de computador e o baixo desempenho escolar, mas suscita, sem sombra de dúvidas, reflexôes quanto ao uso que é feito do computador na e pela escola e quanto à efetiva contribuição que esse artefato pode oferecer à aquisição/construção de conhecimentos escolares.

Como não se sabe que exercícios, lições de casa ou atividades foram propostos pelos professores de matemática, para serem realizados no computador, poder-se-ia supor, também, que as tarefas propostas não eram adequadas à transmissão/construção daquele conhecimento ou mesmo que eram incompatíveis com o uso potencial do computador. Ou seja, se a pergunta se restringisse exclusivamente à realização de liçōes e exercícios de matemática, passados pelo professor, independente do uso do computador, e os resultados encontrados fossem os 
mesmos, seria correto concluir que a realização "intensa” de tarefas escolares, propostas por professores de matemática, provoca baixo desempenho em matemática, sem que se soubesse a natureza dessas tarefas? Provavelmente, não. $\mathrm{O}$ estudo em questão certamente permite concluir que as tarefas que foram realizadas no computador impactaram negativamente na aquisição de conhecimento, mas, a nosso ver, não dá condições para se afirmar que isso se deve necessariamente ao fato de terem sido realizadas no computador.

Cabe, então, retomar o alerta, tantas vezes feito, de que a simples utilização de computadores interfere muito pouco na qualidade do ensino e não leva, necessariamente, os estudantes a aprenderem mais. O uso de tecnologias, associado a propostas pedagógicas concebidas/implementadas a partir de concepções de ensino ancoradas na lógica da produção/distribuição centralizada (de um para muitos) de informaçôes e de conteúdos e que entendem a aprendizagem como etapas a serem controladas passo-a-passo, fundadas basicamente na memorização e na repetição, certamente não vai produzir bons resultados, independente dos recursos que essas tecnologias possam vir a oferecer.

Se tomadas a partir de outros parâmetros, as tecnologias digitais podem contribuir com a tarefa de ensinar, sobretudo no que se refere ao acesso, organização e gestão dos conteúdos a serem ensinados/aprendidos. Uma das possibilidades seria, por exemplo, o compartilhamento por professores e estudantes de ambientes de criação colaborativa (disponíveis na internet, gratuitamente), nos quais podem ser arquivados diferentes tipos de documentos (textos, vídeos, registros de aulas, previsão dos conteúdos a serem trabalhados e assim por diante) e onde podem ser desenvolvidos diferentes tipos de atividades envolvendo a produção e o compartilhamento de conhecimentos. Para Pretto e Assis (2008, p. 82),

(...) a colaboração e o trabalho em rede (...) são princípios necessários à educação, pois se fundamentam na idéia de que os conhecimentos não são "mercadorias" de propriedade de uns poucos, prontas a serem distribuídas para "consumidores" cuja única tarefa seria armazená-las e, no momento oportuno, dar provas de que as possuem.

Para os autores, "a articulação entre cultura digital e educação se concretiza a partir das possibilidades de organização em rede, com apropriação criativa dos meios tecnológicos de produção de informação, 
acompanhada de um forte repensar dos valores, práticas e modos de ser, pensar e agir da sociedade" (idem, ibid.).

Uma revisão de literatura sobre tecnologias móveis e aprendizagem (Naismith et al., 2004), realizada por pesquisadores da Universidade de Birmingham, na Inglaterra, analisa o potencial dos recursos que estão disponíveis, apontando possibilidades de incorporação dessas tecnologias, tanto na complementação da educação presencial, quanto em estudos realizados totalmente a distância. Explorar as potencialidades dessas tecnologias, experimentar o que elas têm a oferecer à escola, sobretudo no que se refere à aprendizagem 'colaborativa' e à interatividade, é uma boa maneira de integrá-las ao cotidiano escolar, sem supervalorizar seu potencial. Além disso, entender a relação que crianças e jovens têm com essas tecnologias, como as utilizam e para quê, como aprendem e o que aprendem em contato com elas, ao invés de proibir seu uso na escola, pode nos ajudar a encontrar maneiras de incorporálas, de forma mais adequada e produtiva, aos ambientes e práticas escolares. Nesse contexto, se tomadas apenas como um robusto reservatório de informações, como uma biblioteca babilônica de fácil acesso, as tecnologias digitais e a internet certamente prestarão um importante serviço à escola, mas não serão aproveitadas no que de melhor têm a oferecer.

Ao contrário dos que supõem que as novas gerações são cognitiva e culturalmente medíocres, se comparadas às geraçôes de seus pais e avós, ${ }^{5}$ acreditamos que as novas gerações não são nem mais nem menos cultivadas ou inteligentes do que as anteriores, mas, ao que tudo indica, desenvolveram formas de lidar com a informação e de construir conhecimentos diferentes daquelas com as quais aprendemos a lidar e que tomamos como referência para ensinar. A escola terá melhores condições de cumprir seu papel de escolarizar as novas geraçôes de nativos digitais se conseguirmos levar em conta, na organização do currículo, nas práticas escolares e na escolha de nossos métodos, formas de aprender que não se enquadram em nossos paradigmas.

\section{Recebido e aprovado em agosto de 2008.}

\section{Notas}

1. Um paladino é um herói cavalheiresco, errante e destemido, de carater inquestionável que segue sempre o caminho da verdade, lei e ordem, sempre disposto a proteger os fracos e 
lutar por causas justas. A palavra Paladino vem do latim palatinus (relativo a palácio), por sua vez derivado do Palatino, uma das sete colinas de Roma. Este personagem lendário da Idade Média remonta aos 12 pares de Carlos Magno que aparecem no poema $A$ Canção de Rolando que conta a história de Rolando e os doze pares da França na batalha de Roncesvalles. Também as lendas célticas consideram paladinos os lendários Rei Artur e Os Cavaleiros da Távola Redonda (Grimal, 1997).

2. Zeus enviou Pandora como presente a Epimeteu ("aquele que pensa depois"), que havia sido avisado por Prometeu para não aceitar nenhum presente dos deuses. Pandora chega trazendo em suas mãos um grande vaso (pithos $=$ jarro) fechado que trouxera do Olimpo como presente de casamento ao marido. Encantado com Pandora, desconsidera as recomendações do irmão e Pandora abre-o diante dele e, de dentro, como nuvem negra, escapam todas as maldiçóes e pragas que assolam todo o planeta. Pandora ainda tenta fechar a ânfora divina, mas é tarde demais: ela estava vazia, com a exceção da "esperança", que permaneceu presa junto à borda da caixa. Deste mito ficou a expressão "caixa de Pandora”, que se usa em sentido figurado quando se quer dizer que alguma coisa, sob uma aparente inocência ou beleza, é na verdade uma fonte de calamidades. Abrir a caixa de Pandora significa que uma ação pequena e bem-intencionada pode liberar uma avalanche de repercussões negativas (Grimal, 1997; Brandão, 1987).

3. A dimensão desiderativa constitui os desejos, as emoçôes e os afetos do ser humano, subordinada, em parte, à realidade subjetiva. A dimensão racional diz respeito à parte cognitiva da pessoa e, de certo modo, subordinada às condiçóes impostas pela realidade objetiva. A dimensão contextual/relacional (dimensão social) é o resultado de todas as experiências vividas pelo ser humano desde que nasce, dentro do contexto social e da época em que vive.

4. Naismith et al. (2004) classificam as tecnologias móveis em portáteis e estáticas, no que se refere ao acesso, e em pessoal e compartilhada, no que se refere à interação (p. 7-8). Entre as tecnologias móveis portáteis encontram-se telefones celulares, telefones multifuncionais ou smartphones (que interam câmera de fotografia e de vídeo, armazenamento de dados, captura e execução de música, acesso à internet), PDAs (Assistente Pessoal Digital computador de bolso com tela sensível ao toque e lápis virtual para inserção de texto, com recursos de acesso à internet) e consoles portáteis de videogames (tais como o Game Boy, da Nintendo) e os laptops (ou notebooks). Estas são consideradas tecnologias de uso pessoal.

5. De acordo com a resenha publicada no Los Angeles Times/Book (Drutman, 2008), Mark Bauerlein afirma expressamente, no livro The dumbest generation: how the digital age stupefies young Americans and jeopardizes our future, or don't trust anyone under 30, recém-publicado nos Estados Unidos, que as novas geraçôes são mais estúpidas do que as anteriores, em função de um suposto mal-uso da internet e que, por essa razão, o futuro daquele país estaria seriamente comprometido.

\title{
Referências
}

\begin{abstract}
BARRETO, A.A. As palavras voam, a escrita permanece: a aventura do hipertexto. DataGramaZero: Revista de Ciência da Informação, Rio de Janeiro, v. 5, n. 5, p. 1-10, 2004. Disponível em: <http:// www.dgz.org.br/out04/F_I_art.htm>. Acesso em: 2 ago. 2008.
\end{abstract}


BARTHES, R. Elementos de semiologia. São Paulo: Cultrix, 1964. BATTRO, A.M.; FISHER, K.W.; LÊNA, P.J. (Org.). The educated brain: essays in neuroeducation. Cambridge: Cambridge University, 2008.

BRANDÃO, J.S. Mitologia grega. Rio de Janeiro: Vozes, 1987. v. 1.

BRANDÃO, Z;; MARTINEZ, M.H. Elites escolares e capital cultural. Revista do SOCED, Rio de Janeiro, n. 3, 2006. Disponível em: $<$ http://www.maxwell.lambda.ele.puc-rio.br/cgi-bin/db2www/ PRG_1167.D2W/input?CdLinPrg=pt>. Acesso em: 22 jul. 2008.

CHARTIER, R. A história cultural entre práticas e representaçōes. Rio de Janeiro: Bertrand, 1999.

CGI (COMITÊ GESTOR DA INTERNET NO BRASIL). Relatório de Pesquisa sobre o uso das Tecnologias da Informaçāo e da Comunicação no Brasil, 2007. Disponível em: <http://www.cgi.br>. Acesso em: 18 jul. 2008.

DAMASIO, A. O erro de Descartes: emoção, razão e o cérebro humano. São Paulo: Cia das Letras, 1996.

DRUTMAN, L. 'The Dumbest Generation' by Mark Bauerlein: how dumb are we? Thanks to the internet, dumb and dumber, this author writes. 2008. Disponível em: <http://www.latimes.com/features/ books/la-et-book5-2008jul05,0,3980465.story>

DUARTE, R.; MIGLIORA, R.; LEITE, C. Crianças e televisão: o que elas pensam sobre o que aprendem com a tevê. Revista Brasileira de Educą̧ão, Rio de Janeiro, v. 11, n. 33, p. 497-509, 2006.

DWYER, T. et al. Desvendando mitos: os computadores e o desempenho no sistema escolar. Educą̧ão \& Sociedade, Campinas, v. 28, n. 101, p. 1303-1328, 2007.

ECO, U. A estrutura ausente. São Paulo: Perspectiva, 1987.

FLAVELL, J.H. Development métacognitif. In: Bideaud J.; RichelLe, M. (Org.). Psychologie développmentale: problémes et réalités. Bruxelles: Pierre Mardaga, 1985. p. 29-41. 
O contexto dos novos recursos tecnológicos de informação e comunicação e a escola

FREUD, S. Projeto para uma teoria científica In: FreUd, S. Edição standard brasileira das obras completas de Sigmund Freud. Rio de Janeiro: Imago, 1977. v. 1.

GRIMAL, P. Dicionário de mitologia grega e romana. Trad. de Victor Jabouille. Rio de Janeiro: Bertrand Brasil, 1997.

KEEGAN, D. The future of learning: from e-learning to m-learning. Hagen: Fern Universität, 2002.

LEWIN, K. Teoria de campo em Ciência Social. São Paulo: Pioneira, 1951.

MAIA, M.V.C.M.; BITTENCOURT, M.I. Do carrinho de rolimã ao vídeo game: reflexôes sobre a criatividade e a autoria de pensamento na contemporaneidade. Revista Vivência, Natal, n. 31, p. 111-120, 2006.

MAMEDE-NEVES, M.A.C. Os pensares. In: MAmede-Neves, M.A.C. Aprendendo aprendizagem. 3. ed. Rio de Janeiro: PUC-RIO/CCE, 2004. (CD-ROM).

MAMEDE-NEVES, M.A.C. O jovem no centro da dimensão oculta da internet. In: NicolaCI-DA-CosTA, A.M. (Org.). Cabeças digitais: o cotidiano na era da informação. Rio de Janeiro: PUC-RIO; São Paulo: Loyola, 2006. p. 181-190.

MAMEDE-NEVES, M.A.C. Jovens em rede. Rio de Janeiro: PUC-RIO, 2008. (Relatório de Pesquisa Institucional CNPq).

MAMEDE-NEVES, M.A.C.; PEDROSA, S.M.P.A.; COSTA, A.V.F. Jovem jornal: ecos de uma pesquisa. Rio de Janeiro: $T+8,2007$.

NAISMITH, L. et al. Literature review in mobile technologies and learning. Futurelab, Bristol, 2004. Disponível em: <www.futurelab.org.uk/resources/publications_reports_articles/literature_reviews/Literature_ Review203>. Acesso em: 18 jul. 2008.

NUNES, J.M.G. Linguagem e cognição. Rio de Janeiro: LTC, 2006.

OSTROWER, F. A sensibilidade do intelecto. 7. ed. Rio de Janeiro: Elsevier, 1998.

PAIN, S. A função da ignorância. Porto Alegre: Artes Médicas, 1999. 
PICANÇO, A.A. et al. Conversando sobre interatividade. 2000. Disponível em: <http://www.faced.ufba.br/ -dept02/sala_interativa/ texto_grupo.html >. Acesso em: 2 jul. 2008.

PRENSKY, M. Digital natives, digital immigrants. On the Horizon, NBC University, v. 9, n. 5, p.1-2 oct. 2001. Disponível em: <http:// www.marcprenky.com/wrinting/default.asp $>$. Acesso em: 29 jul. 2008.

PRETTO, N.; ASSIS, A. Cultura digital e educação: redes já. In: Pretto, N.; Silveira, A. (Org.). Além das redes de colaboração: internet, diversidade cultural e tecnologias do poder. Salvador: EDUfBA, 2008.

RIVOLTELLA, P.C. (Org.). Screen generation: gli adolescenti e le prospettive nell'educazione nell'età de media digitali. Milano: Vita \& Pensiero, 2006.

ROUANET, S.P. A razão nômade. Rio de Janeiro: UfRJ, 1993.

SANTAELlA, L.; NOTH, W. Comunicação e semiótica. São Paulo: Hacker, 2004.

SILVA, M. Um convite à interatividade e à complexidade: novas perspectivas comunicacionais para a sala de aula. In: GonÇALVES, M.A.R. (Org.). Educação e cultura: pensando em cidadania. Rio de Janeiro: Quartet, 1999.

SIMMEL, G. O problema da sociologia. In: Moraes Filho, E. (Org.). Georg Simmel: sociologia. Trad. de Evaristo de Moraes Filho. São Paulo: Atica, 1983. 